\title{
Inferior Alveolar Nerve Lateralization and Transposition for Dental Implant Placement. Part I: a Systematic Review of Surgical Techniques
}

\author{
Boris Abayev $^{1}$, Gintaras Juodzbalys ${ }^{1}$ \\ ${ }^{1}$ Department of Maxillofacial Surgery, Lithuanian University of Health Sciences, Kaunas, Lithuania.
}

\author{
Corresponding Author: \\ Boris Abayev \\ Sukileliu pr. 108-21, LT-49240, Kaunas \\ Lithuania \\ Phone: +37063849781 \\ E-mail: suboris11@gmail.com
}

\begin{abstract}
Objectives: The purpose of this first part of a two-part series was to review the literature concerning the indications, contraindications, advantages, disadvantages and surgical techniques of the lateralization and transposition of the inferior alveolar nerve, followed by the placement of an implant in an edentulous atrophic posterior mandible.

Material and Methods: A comprehensive review of the current literature was conducted according to the PRISMA guidelines by accessing the NCBI PubMed and PMC database, academic sites and books. The articles were searched from January 1997 to July 2014 and comprised English-language articles that included adult patients between 18 and 80 years old with minimal residual bone above the mandibular canal who had undergone inferior alveolar nerve (IAN) repositioning with a minimum 6 months of follow-up.

Results: A total of 16 studies were included in this review. Nine were related to IAN transposition, 4 to IAN lateralization and 3 to both transposition and lateralization. Implant treatment results and complications were presented.

Conclusions: Inferior alveolar nerve lateralization and transposition in combination with the installation of dental implants is sometimes the only possible procedure to help patients to obtain a fixed prosthesis, in edentulous atrophic posterior mandibles. With careful pre-operative surgical and prosthetic planning, imaging, and extremely precise surgical technique, this procedure can be successfully used for implant placement in edentulous posterior mandibular segments.
\end{abstract}

Keywords: alveolar bone atrophy; dental implants; fifth cranial nerve injury; jaw surgery; mandibular nerve; paresthesia.

Accepted for publication: 27 March 2015

To cite this article:

Abayev B, Juodzbalys G. Inferior Alveolar Nerve Lateralization and Transposition for Dental Implant Placement. Part I: a Systematic Review of Surgical Techniques.

J Oral Maxillofac Res 2015;6(1):e2

URL: http://www.ejomr.org/JOMR/archives/2015/1/e2/v6n1e2.pdf

doi: $10.5037 /$ jomr.2015.6102 


\section{INTRODUCTION}

Tooth loss is one of the common causes of reduced quality of life in adults. Dental implants have become a widely accepted treatment option for patients with both partially and complete edentulous posterior mandibles. Rehabilitation of edentulous posterior mandibular regions with severe ridge atrophy using implants is subject to anatomical, surgical and biological difficulties and poses a challenge to dental teams [1]. Osseointegrated dental implants are often placed in the posterior mandible, mostly to support fixed restorative prostheses. In many cases, the bone has so severely atrophied that sufficiently long fixtures cannot be placed without encroaching on the inferior alveolar nerve (IAN). In this situation, restorative options include the use of short fixtures, onlay bone grafting to increase ridge height, and more complicated and detailed imaging analysis to allow positioning of implants alongside, rather than into, the nerve canal during the procedure. Another option is to move the IAN laterally from its canal by either nerve lateralization (IANL). With nerve lateralization, the IAN is exposed and traction is used to deflect it laterally while the implants are placed. The IAN is then left to fall back into position, against the fixtures. With this procedure, there is no interference with the incisive nerve. With nerve transposition, a corticotomy is done around the mental foramen and the incisive nerve is transacted, such that the mental foramen is repositioned more posteriorly.

In the posterior mandible, the bone quality may not be as good as it is in the anterior mandible. In particular, if shorter implants are used to ensure that there is no encroachment on the nerve canal, initial implant stability will be unicortical. In addition, there is a risk to the IAN as the operator tries to maximise implant length on the basis of measured available bone height. The advantages of IANT include the ability to place longer fixtures and to engage 2 cortices for initial stability [2]. Kan et al. [3] pointed out that the amount of bone superior to the mandibular canal (MC) is often insufficient for the placement of fixtures of the ideal length. In addition, the existing bone that is superior to the MC is often of poorer quality than its cortical counterpart. These factors and the fact that shorter implants have been associated with higher failure rates have led to the development of methods of IAN repositioning that allow placement of longer fixtures; with these methods, the inferior cortex of the mandible is engaged, which leads to greater initial stability. Therefore, the purpose of the present paper was to review the literature concerning the indications, contraindications, advantages, disadvantages and the surgical techniques of the lateralization and transposition of the inferior alveolar nerve, followed by the implants placement in an edentulous atrophic posterior mandible.

\section{MATERIAL AND METHODS IAN lateralization (IANL) and transposition (IANT) definition}

IANL and IANT are surgical procedures that reposition the IAN for the purpose of implant placement without bone augmentation. The buccal cortex surrounding the $\mathrm{MC}$ is removed to allow IAN repositioning. This procedure raises the risk of neuropathies, such as paresthesia, hypoesthesia, and anaesthesia of the IAN [4]].

IANL is defined as the lateral reflection of the IAN without incisive nerve traction (preservation of the incisive nerve and lateralization of inferior alveolar neurovascular bundle posterior to the mental foramen) []ㅡ; exposure and traction are used to deflect the IAN laterally while the implants are placed. The IAN is then left to fall back in against the fixtures $[2,3,5]$.

During the IANT procedure, a corticotomy is done around the mental foramen and the incisive nerve is transacted (incisive neurovascular bundle is sacrificed), to allow transposition of both the mental foramen and the IAN such that the mental foramen is repositioned more posteriorly $[\underline{2}, \underline{3}, \underline{5}]$.

\section{History}

The first case of IAN repositioning was reported by Alling (1977) [6] to rehabilitate patients with severe atrophy for dentures. In 1987, Jenson and Nock [7] carried out IANT for the placement of dental implants in posterior mandibular regions. According to subjective criteria, sensory function of the mental nerve returned to normal five weeks post-operative. No objective neurosensory evaluation was performed. There is limited information about implants survival rate. In 1992, Rosenquist [8] performed the first case series study using IANT followed by 26 implants placement on 10 patients. Neurosensory function of the mental nerve was evaluated objectively using the two-point discrimination (2-PD) method. At one year follow-up, all 10 sites tested normal. He reported an implant survival rate of $96 \%$ and implant survival rate of $93.6 \%$ for this procedure; therefore, this technique was accepted as the best-practice treatment modality for reconstruction of the dentoalveolar system with dental implants in the posterior mandible. As a result, 
this technique is constantly undergoing improvement. IANT is a new procedure that needs further refinements in terms of technique and instrumentation to decrease complications [9].

\section{Protocol and registration}

The review is registered in international prospective register of systematic reviews 'PROSPERO' [10].

The protocol can be accessed at:

http://www.crd.york.ac.uk/prospero/display_record. asp?ID=CRD42015016265\#.VMoTYZ1FAyY

Registration number: CRD42015016265.

\section{Eligibility criteria \\ Types of publication}

The review included studies, case reports, clinical trials on human subjects that were published in English between January 1997 and July 2014, and included a minimum of 6 months of follow-up. Letters and $\mathrm{PhD}$ theses were excluded, as well as abstracts and reviews and studies on animals.

\section{Information sources}

The information source was the MEDLINE (NCBI PubMed and PMC) database and other scientific electronic sources.

\section{Search}

According to the PRISMA guidelines, an electronic search was conducted using the MEDLINE (NCBI PubMed and PMC) database to locate articles concerning IAN lateralization or transposition and implant placement in an edentulous atrophic posterior mandible. The search terms used were: "INFERIOR ALVEOLAR NERVE LATERALIZATION", “I N F E R I O R A L V E O L A R NERVE REPOSITIONING", "INFERIOR ALVEOLAR NERVE TRANSPOSITION", "IMPLANTS IN ATROPHIC POSTERIOR MANDIBLE + REPOSITIONING", "INFERIOR ALVEOLAR NERVE TRANSPOSITION + MENTAL", "IMPLANTS IN ATROPHIC POSTERIOR MANDIBLE + LATERALIZATION", "IMPLANTS IN ATROPHIC POSTERIOR MANDIBLE + TRANSPOSITION", "MANDIBULAR ATROPHY + REPOSITIONING", AND "INFERIOR ALVEOLAR NERVE + MINIMAL BONE HEIGHT".

Due to the low number of relevant articles and to ensure the sensitivity of the systemic review process, articles were searched from January 1997 to
July 2014. Bibliographies of the selected articles were also manually searched. Titles derived from this broad search were independently screened by two authors based on the inclusion criteria. Disagreements were resolved by discussion. Full reports were obtained for all the studies that were deemed eligible for inclusion in this paper. Figure 1 illustrates the flow diagram of present article selection according to PRISMA guidelines [11].

\section{Study selection \\ Inclusion and exclusion criteria}

Inclusion criteria for the selection were:

- Articles regarding to IANL and IANT procedures;

- All articles in English;

- Clinical reports with minimum 6 months followup;

- Information regarding implant osseointegration and survival;

- Studies on adult (between the ages 18 and 80) human beings, with no immunologic diseases, uncontrolled diabetes mellitus, osteoporosis, or other contraindicating systemic conditions.

Exclusion criteria for the selection were:

- Clinical reports with no minimum 6 months of follow-up;

- Not enough information regarding the selected topic;

- No information regarding implant osseointegration and survival;

- Studies on animals;

- Studies of patients with immunologic diseases, uncontrolled diabetes mellitus, osteoporosis or other contraindicating systemic conditions;

- Studies of adolescents (under 18 years of age) and elderly people (over 80).

\section{Article review and data extraction}

Article review and data extraction was performed according to a PRISMA flow diagram (Figure 1).

The search displayed 876 results from the NCBI PMC and PubMed databases, and 3 results from other sources (dental-tribune.com, acta.tums.ac.ir, hindawi.com/journals). A total of 879 search results were screened. Preliminary exclusion was made by duplication and relevancy $(\mathrm{n}=841)$. A total of 38 titles and abstracts were selected according to relevancy after the removal of duplications. Exclusion was made by information amount regarding selected topic $(n=12)$. Twenty-six articles were examined. Another exclusion was made based upon follow-up time $(n=6)$ and information regarding 


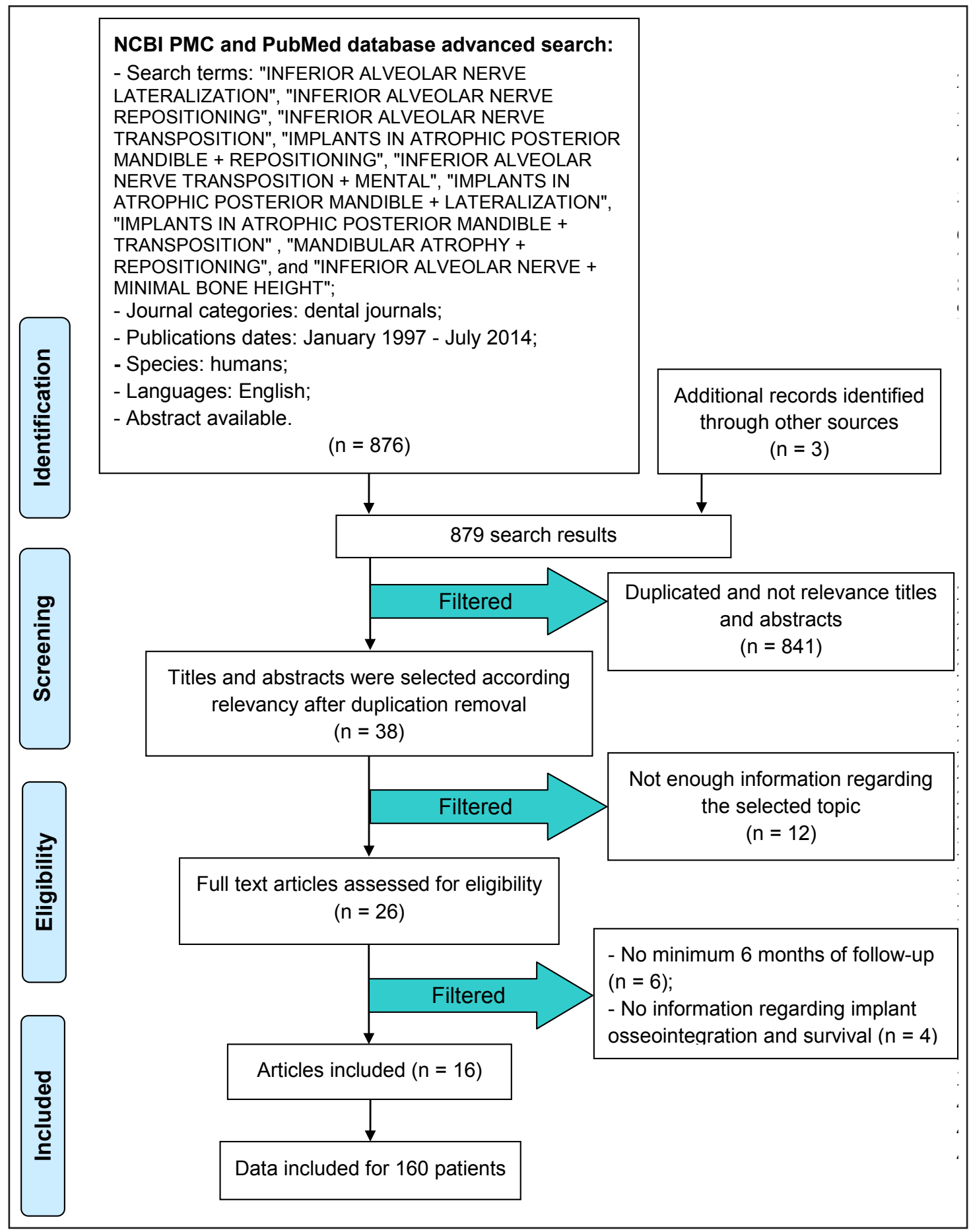

Figure 1. PRISMA flow diagram.

implant osseointegration and survival $(\mathrm{n}=4)$. Finally, 16 articles were included in the systematic review. Data was included for 160 patients.

\section{Population selection}

Studies of adult human beings between 18 and 80 years of age with minimal residual bone above the $\mathrm{MC}$, in which IANL and IANT + implant placement had been performed, were selected.

\section{Data collection process}

Data was independently extracted from reports in the form of variables according to the aim and themes of the present review as listed below.

\section{Outcome measures}

The review aims to achieve the following:

1. To describe the purpose (indications and contraindications) of IANL and IANT. 
2. To describe the current surgical techniques used for IANL and IANT with simultaneous implant placement.

3. To describe the advantages and disadvantages of the IANL and IANT procedures.

\section{Risk of bias assessment}

Risk of bias (e.g., lack of information or selective reports on variables of interest) was assessed at the study level. The risks were indicated as lack of precise information of interest in each individual study that can blind the reader from particular information about the examined samples. The Cochrane Collaboration tool for assessing risk of bias [12] was used to assess bias across the studies that could affect cumulative evidence.

\section{RESULTS}

\section{Study selection}

The search displayed 876 results from the NCBI PMC and PubMed databases, and 3 results from other sources (dental-tribune.com, acta.tums.ac.ir, hindawi.com/journals). A total of 879 search results were screened. Preliminary exclusion was made by duplication and relevancy $(\mathrm{n}=841)$. A total of 38 titles and abstracts were selected according to relevancy after duplications removal. Exclusion was made according to information amount regarding selected topic $(n=12)$. Twenty-six full-text articles were in the end, assessed for eligibility. During the eligibility stage, articles that did not meet the inclusion and exclusion criteria where filtered as follows: no minimum 6 months of follow-up $(n=6)$ and no information regarding implant osseointegration and survival $(\mathrm{n}=4)$. In the end, 16 articles that included data on 160 patients were utilised for the systematic review (Figure 1).

\section{Study characteristics}

A total of 16 studies were included in this review. Nine were related to IANT, 4 to IANL and 3 to both IANT and IANL (Table 1).

\section{Risk of bias within studies}

The Cochrane Collaboration bias summary for potential bias was used to assess the quality of studies and identify papers with intrinsic flaws in method and design [12]. After analysing the risk of bias (Table 2), we found that six authors [ $[\underline{13-17]}$ selected the patients randomly. In four studies [1-3, $\underline{5}]$, the surgical procedure was not performed by the authors; and in two studies $[1, \underline{3}]$, the method of implant osseointegration evaluation was not mentioned.

\section{Results of individual studies}

Results of individual studies of implant treatment using are shown in Table 3.

Table 1. Description of studies included in the review

\begin{tabular}{|c|c|c|c|}
\hline Study & $\begin{array}{c}\text { Year of } \\
\text { publication }\end{array}$ & Procedure performed & $\begin{array}{c}\text { Number } \\
\text { of patients }\end{array}$ \\
\hline Lorean et al. [1] & 2013 & Transposition and repositioning & 57 \\
\hline Morrison et al. [2] & 2002 & Transposition & 12 \\
\hline \multirow{2}{*}{ Kan et al. [ $\underline{3}]$} & \multirow{2}{*}{1997} & Lateralization & 10 \\
\hline & & Transposition & 5 \\
\hline Peleg et al. []] & 2002 & Lateralization & 10 \\
\hline \multirow{2}{*}{ Khajehahmadi et al. [ $\underline{5}]$} & \multirow{2}{*}{2013} & Lateralization & 10 \\
\hline & & Transposition & 11 \\
\hline Dal Ponte et al. [13] & 2011 & Transposition & 1 \\
\hline Vasconcelos et al. [14] & 2008 & Transposition & 1 \\
\hline Suzuki et al. [15] & 2012 & Lateralization & 1 \\
\hline Chrcanovic et al. [16] & 2009 & Transposition & 15 \\
\hline Proussaefs [17] & 2005 & Transposition & 1 \\
\hline Ferrigno et al. [18] & 2005 & Transposition & 15 \\
\hline Kan et al. [19] & 1997 & Transposition & 1 \\
\hline Karlis et al. [20] & 2003 & Transposition & 1 \\
\hline Proussaefs [21] & 2005 & Transposition & 1 \\
\hline Barbu et al. [24] & 2014 & Lateralization & 7 \\
\hline Del Castillo Pardo et al. [26] & 2008 & Lateralization & 1 \\
\hline
\end{tabular}


Table 2. Assesment of the risks of bias

\begin{tabular}{|c|c|c|c|}
\hline Study & $\begin{array}{l}\text { Implant osseointegration was not } \\
\text { evaluated with Perio-Test Unit or } \\
\text { evaluation method was not mentioned }\end{array}$ & $\begin{array}{c}\text { Random selection of } \\
\text { patients }\end{array}$ & $\begin{array}{l}\text { The operation was } \\
\text { not performed by } \\
\text { the authors }\end{array}$ \\
\hline Lorean et al. $[1]$ & + & - & + \\
\hline Morrison et al. [2] & - & - & + \\
\hline Kan et al. []ㅡ & + & - & + \\
\hline Peleg et al. [4] & - & - & - \\
\hline Khajehahmadi et al. []] & - & + & + \\
\hline Dal Ponte et al. [13] & - & + & - \\
\hline Vasconcelos et al. [14] & - & + & - \\
\hline Suzuki et al. [15] & - & + & - \\
\hline Chrcanovic et al. [16] & - & + & - \\
\hline Proussaefs [1]] & - & + & - \\
\hline Ferrigno et al. [18] & - & - & - \\
\hline Kan et al. [19] & - & - & - \\
\hline Karlis et al. [20] & - & - & - \\
\hline Proussaefs [21] & - & - & - \\
\hline Barbu et al. [24] & - & - & - \\
\hline Del Castillo Pardo et al. [26] & - & - & - \\
\hline
\end{tabular}

\section{DISCUSSION}

From the results of individual study data (Table 3), we can conclude that the most popular surgical technique for IAN repositioning was IANT. It was calculated that $51.44 \%(107 / 208)$ of all operations performed utilised IANT, and 48.56\% (101/208) utilised IANL. Number of implants placed after IANT was 211, while number of implants placed after IANL was 95. In the study by Lorean et al. [1] (in which 68 IANL and 11 IANT were performed), the authors failed to mention how many implants were placed during each procedure. Implant survival rate was $100 \%$ in 10 out of 16 studies. In Lorean et al. study [1], implant survival rate was 99.57\%; in Chrcanovic et al. [16] it was $88 \%$; in Ferrigno et al. [18], it was $95.7 \%$; and Kan et al. []] presented a $93.8 \%$ implant survival rate. The lowest implant survival rates were found in Kan et al. [19] with 33.33\% and Karlis et al. [20] with $0 \%$. The most popular method of implant osseointegration evaluation was panoramic radiograph (12/16 studies). In two studies $[17,21]$, both of which were performed by the same author (Proussaefs), the method of implant osseointegration evaluation was a Perio-Test unit (Siemens, Bensheim, Germany); while in two other studies (Lorean et al. [1], Kan et al. [3]), the implant osseointegration evaluation method was not mentioned.
The purpose (indications and contraindications) of IANL and IANT

\section{Indications}

The study of number selected articles [9, $22-$ 25] revealed the following indications of IANL and IANT:

1. The major reason for using this technique is to prevent IAN injury during implant placement in edentulous posterior atrophic mandibles.

2. Class IV, V, or VI of Cawood and Howell [25] with extrusion of the antagonist tooth and reduced prosthetic free space.

3. Class V or VI of Cawood and Howell [25] with presence of interforaminal teeth (patients were not candidates for interforaminal implant-prosthetic methods).

4. Class V or VI of Cawood and Howell [25] if the patient desires a fast implant-prosthetic rehabilitation with predictable outcomes.

5. In orthognathic surgeries, such as lower border shaving and total mandibular subapical osteotomy.

6. In the pre-prosthetic surgery.

7. In the anastomosis and repairing of a disrupted IAN.

8. Preservation of IAN in cancer surgery in the posterior mandible.

9. When placement of short implants is not a viable option (in case of severely atrophic mandibles when the residual bone above $\mathrm{MC}$ ranges between 0.5 and $1.5 \mathrm{~mm})$. 
Table 3. Results of individual studies

\begin{tabular}{|c|c|c|c|c|c|c|}
\hline Study & \begin{tabular}{|c|} 
Number of \\
IANL and \\
IANT procedures
\end{tabular} & $\begin{array}{c}\text { Number of } \\
\text { implants } \\
\text { placed }\end{array}$ & $\begin{array}{c}\text { Number of } \\
\text { implants } \\
\text { lost }\end{array}$ & $\begin{array}{c}\text { Implant } \\
\text { survival } \\
\text { rate }\end{array}$ & $\begin{array}{c}\text { Method of implant } \\
\text { osseointegration } \\
\text { evaluation }\end{array}$ & Results \\
\hline $\begin{array}{l}\text { Lorean et al. } \\
{[\underline{1}]}\end{array}$ & $\begin{array}{l}68 \text { - IANL } \\
11 \text { - IANT }\end{array}$ & 232 & 1 & $99.57 \%$ & Not mentioned & $\begin{array}{l}\text { One implant loss was observed during follow-up period } \\
\text { (average } 20.62 \text { months). }\end{array}$ \\
\hline $\begin{array}{l}\text { Morrison } \\
\text { et al. [2] }\end{array}$ & 20 - IANT & 30 & 0 & $100 \%$ & Panoramic X-ray & $\begin{array}{l}\text { All } 30 \text { implants had successfully integrated. No evidence } \\
\text { of infections, wound dehiscences, fractures or other } \\
\text { serious complications. }\end{array}$ \\
\hline Kan et al. [ $\underline{3}]$ & $\begin{array}{l}10 \text { - IANL } \\
5 \text { - IANT }\end{array}$ & 64 & 4 & $93.8 \%$ & Not mentioned & $\begin{array}{l}\text { Four of } 64 \text { implants had been removed. Two implants } \\
\text { were lost due to infection after the patient had sustained a } \\
\text { mandibular fracture. Two other implants were lost due to } \\
\text { non-integration. }\end{array}$ \\
\hline Peleg et al. [4]] & 10 - IANL & 23 & 0 & $100 \%$ & Panoramic X-ray & All implants were clinically osseointegrated. \\
\hline $\begin{array}{l}\text { Khajehahmadi } \\
\text { et al. [ }[5]\end{array}$ & 28 - IANT & 65 & 0 & $100 \%$ & Panoramic X-ray & $\begin{array}{l}\text { All implants survived and were subject to prosthodontic } \\
\text { treatments. No evident of failure with at least } 1 \text { year of } \\
\text { follow-up. }\end{array}$ \\
\hline $\begin{array}{l}\text { Dal Ponte } \\
\text { et al. [13] }\end{array}$ & 1 - IANT & 2 & 0 & $100 \%$ & Panoramic X-ray & $\begin{array}{l}\text { On } 2 \text { and } 7 \text { years follow-up panoramic } \mathrm{X} \text {-rays visible good } \\
\text { osseointegration of implants without abnormality. }\end{array}$ \\
\hline $\begin{array}{l}\text { Vasconcelos } \\
\text { et al. [14] }\end{array}$ & 1 - IANT & 2 & 0 & $100 \%$ & Panoramic X-ray & $\begin{array}{l}\text { Seven months after surgical procedure revealed excellent } \\
\text { results. }\end{array}$ \\
\hline $\begin{array}{l}\text { Suzuki et al. } \\
{[\underline{15}]}\end{array}$ & 1 - IANL & 2 & 0 & $100 \%$ & Panoramic X-ray & $\begin{array}{l}\text { In the postoperative period of } 6 \text { months, satisfactory } \\
\text { results have been shown as regards to soft and hard tissues } \\
\text { wound healing and temporary prosthetic rehabilitation. }\end{array}$ \\
\hline $\begin{array}{l}\text { Chrcanovic } \\
\text { et al. }[\underline{16}]\end{array}$ & 18 - IANT & 25 & 3 & $88 \%$ & Panoramic X-ray & Three implants did not integrate. \\
\hline $\begin{array}{l}\text { Proussaefs } \\
{[\underline{17]}}\end{array}$ & 1 - IANT & 2 & 0 & $100 \%$ & Perio-Test Unit & $\begin{array}{l}\text { The implants appeared clinically osseointegrated. } \\
\text { Three years post-loading revealed no clinical signs of } \\
\text { pathosis (i.e., mobility, probing depth }<3 \mathrm{~mm} \text {, pain, } \\
\text { BOP) }\end{array}$ \\
\hline $\begin{array}{l}\text { Ferrigno et al. } \\
{[\underline{18]}}\end{array}$ & 19 - IANT & 46 & 2 & $95.7 \%$ & $\begin{array}{l}\text { Clinic and } \\
\text { radiographic } \\
\text { examination }\end{array}$ & $\begin{array}{l}\text { Two implants were lost (early failure). One implant was } \\
\text { lost due to non-integration. Another implant was lost due } \\
\text { to a mandibular fracture. }\end{array}$ \\
\hline Kan et al. [19] & 1 - IANT & 3 & 2 & $33.33 \%$ & Panoramic X-ray & $\begin{array}{l}\text { Three weeks after implants placement the patient } \\
\text { experienced a spontaneous right mandibular fracture } \\
\text { involving two anterior implants, which were finally } \\
\text { removed. }\end{array}$ \\
\hline $\begin{array}{l}\text { Karlis et al. } \\
{[\underline{20}]}\end{array}$ & 1 - IANT & 2 & 2 & $0 \%$ & Panoramic X-ray & $\begin{array}{l}\text { Panoramic X-ray revealed an area of radiolucency around } \\
\text { the most posterior right implant with a non-displaced } \\
\text { linear fracture through the inferior mandibular border. } \\
\text { Finally, both implants were removed. }\end{array}$ \\
\hline $\begin{array}{l}\text { Proussaefs } \\
{[\underline{21}]}\end{array}$ & 1 - IANT & 5 & 0 & $100 \%$ & Perio-Test Unit & $\begin{array}{l}\text { Implants appeared clinically osseointegrated } 6 \text { months } \\
\text { after implant placement (tested with Perio-Test, Siemens, } \\
\text { Bensheim, Germany). Implants were restored with } \\
\text { cement-retained PFM restorations. Three years post } \\
\text { loading X-ray examination revealed minimal marginal } \\
\text { bone loss }(<1 \mathrm{~mm}) \text {. }\end{array}$ \\
\hline $\begin{array}{l}\text { Barbu et al. } \\
{[\underline{24}]}\end{array}$ & 11 - IANL & 32 & 0 & $100 \%$ & Panoramic X-ray & No implant loss was observed during the follow-up. \\
\hline $\begin{array}{l}\text { Del Castillo } \\
\text { Pardo et al. [26] }\end{array}$ & 1 - IANL & 3 & 0 & $100 \%$ & Panoramic X-ray & $\begin{array}{l}\text { Six months after implants placement, no complications } \\
\text { were observed. }\end{array}$ \\
\hline
\end{tabular}

$\mathrm{IANL}=$ inferior alveolar nerve lateralization; IANT = inferior alveolar nerve transposition.

10. Less than $10-11 \mathrm{~mm}$ bone height above the canal, when the quality of the spongy bone does not provide sufficient stability for implant placement.

\section{Contraindications $[9,13]$}

1. If the mandible presents advanced resorption of the alveolar process. 
2. If the patient has poor general health, including systemic diseases that may worsen the patient's health condition after the IAN reposition procedure.

3. Limitations in accessing the surgical site.

4. The patient is susceptible to infection or bleeding.

5. The patient has thick cortical bone buccally and a thin neurovascular bundle.

6. People who become easily stressed out and are over sensitive even towards the smallest surgical complications. Such patients do not have tolerance and compatibility skills and, therefore, are not good candidates for nerve transposition surgery.

The current surgical techniques utilised for lateralization and transposition of IAN with simultaneous implant placement

The preoperative work-up included an assessment of the IAN using appropriate diagnostic records, such as a panoramic radiograph, a computed tomography (CT) scan, casts, diagnostic wax-up, and surgical templates. During preoperative consultation with the patients, the risk of postoperative neurosensory disturbances (ND) that can result following the IAN repositioning is discussed. This possibility gives many patients pause to consider the ramifications of the procedure. To help the patient decide whether this would be tolerable, the clinician can perform a preoperative block with a long-acting local anaesthetic, such as Marcaine, which reproduces symptoms lasting 8 to 16 hours that are similar to the postoperative anaesthesia the patient may experience [4]. Two IAN repositioning techniques have been developed: lateralization and transposition (Table 4). Both procedures include an IAN block plus local infiltrating anaesthesia with vasoconstrictors $[9,26]$. Intravenous sedation is recommended because of the procedure's technique-sensitive nature and the need for patient cooperation [4]. A crestal incision with anterior- and posterior releasing incisions is made, and a labial mucoperiosteal flap is reflected that exposes the alveolar ridge and buccal cortex. The incision should extend at least $1 \mathrm{~cm}$ beyond the anticipated site of the osteotomy. Care is taken during flap reflection to preserve the integrity of the periosteum and the neurovascular bundle where it exits the mental foramen and enters the soft tissue. To increase the flaps' relaxation and improve exposure, dissection is performed below the neurovascular bundle where it exits the mental foramen [4]. The flaps are raised, one lingual to access the alveolar crest, and another vestibular for subperiosteal dissection of the IAN, until sufficient surgical field is obtained [25]. CT is used to locate the approximate area of the mental foramen, after which blunt dissection is used to identify and isolate the mental nerve [4]. From this point onwards, the two surgical techniques are differentiated as described below [25].

\section{IAN transposition (IANT)}

An osteotomy is performed at the mental foramen, drilling around the orifice to obtain a ring of external cortical bone. A window also may be made about 5 $\mathrm{mm}$ ahead of the foramen, in order to avoid damaging the nerve over its anterior loop. An en bloc osteotomy is then made at the external cortical level, or a posterior window is performed in the external cortical layer along the intrabony trajectory of the nerve (Figure 2). A round drill is used to create the window, replacing it with a diamond drill while working close to the MC, to minimise the risk of nerve damage [26]. Bone can be removed using a diamond round bur or piezosurgery device. Bone is removed using a round bur number 700 or 701 , a straight handpiece and copious normal saline for irrigation or a piezosurgery device [9]. In order to secure complete mobilisation of the IAN, the incisor branch, located about $5 \mathrm{~mm}$ from the mental foramen, must be sectioned.

Then, with the nerve fully lateralized, the dental implants are placed under direct visualisation -

Table 4. Inferior alveolar nerve (IAN) replacement division into two distinct surgical procedures, i.e. transposition and lateralization; the steps are outlined below [1]

\begin{tabular}{l|l}
\hline \multicolumn{1}{c|}{ IAN transposition } & \multicolumn{1}{c}{ IAN lateralization } \\
\hline 1. Buccal/lateral bone window & 1. Buccal/lateral bone window \\
\hline 2. Complete osteotomy of the mental foramen & 2. Partial osteotomy of the mental foramen distal portion \\
\hline 3. Micro-dissection of the IAN & 3. Maintaining the integrity of the incisive nerve \\
\hline 4. Incision of the incisive nerve & 4. Gentle buccal traction of the IAN \\
\hline 5. Repositioning of the IAN & $\begin{array}{l}\text { 5. Replacement of the IAN on the implant surface } \\
\text { (with collagen and PRF protective layer) }\end{array}$ \\
\hline
\end{tabular}

6. Incorporation of the IAN into the buccal flap

$\mathrm{PRF}=$ platelet-rich fibrin. 


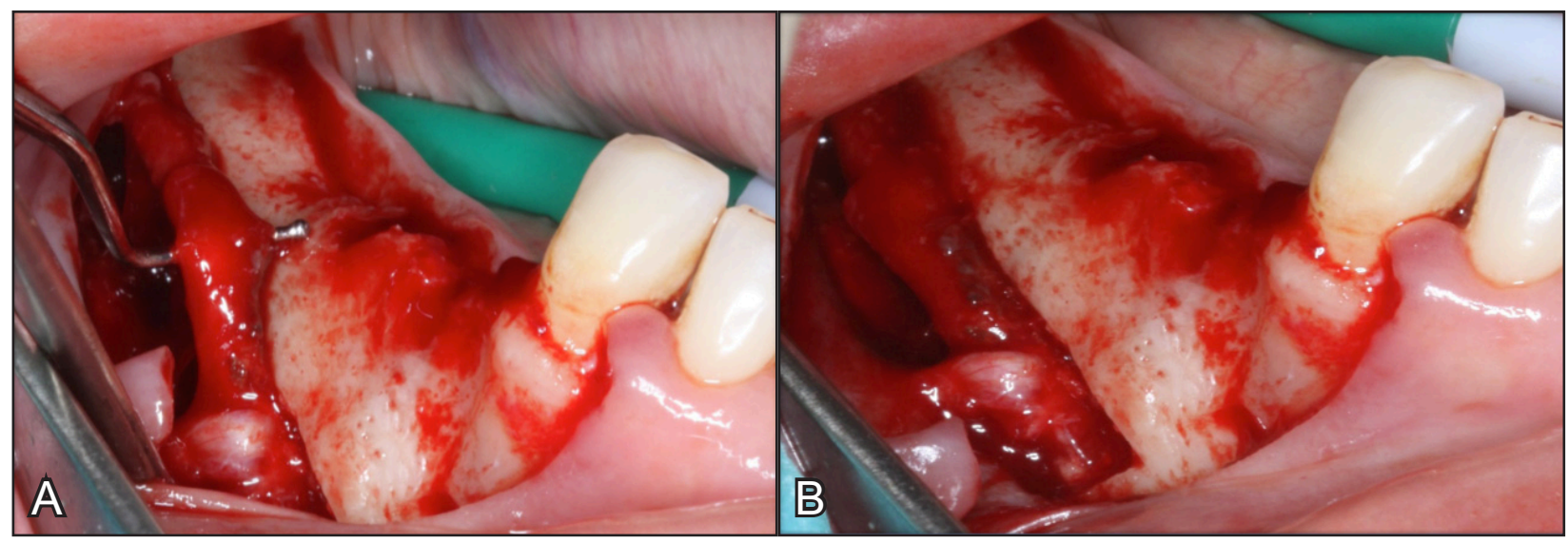

Figure 2. Intraoperative photographs showing inferior alveolar neurovascular bundle transposition. A = before transposition; B = after transposition (courtesy of Dr Dainius Razukevicius, "Kauno Implantologijos Centras" Kaunas, Lithuania).

in this case bicortically, taking advantage of the mandibular basal layer. Once the implants have been positioned, the vestibular cortical layer is replaced in those cases where an osteotomy has been performed, or the nerve is passively positioned against the implants in those cases where cortical drilling has been carried out. In either case, the emergence of the nerve becomes more distal [25].

\section{IAN Lateralization (IANL)}

In this case, neither dissection of the terminal branches of the IAN nor sectioning of the incisor branch is needed. The technique involves the preparation of a cortical bone window (via osteotomy or drilling) that is located posterior to the mental foramen [27] (Figure 3 and 4).

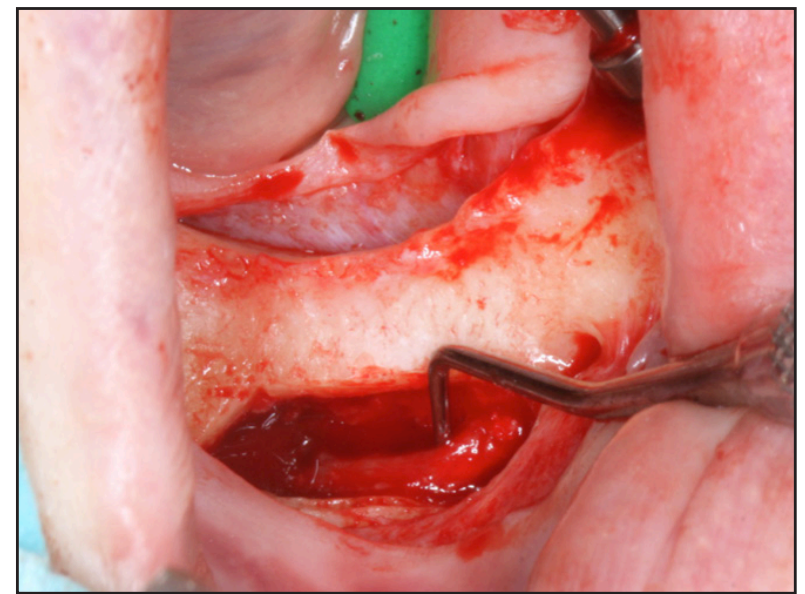

Figure 3. Intraoperative photography showing the inferior alveolar neurovascular bundle lateralization (courtesy of Dr Dainius Razukevicius, "Kauno Implantologijos Centras" Kaunas, Lithuania).

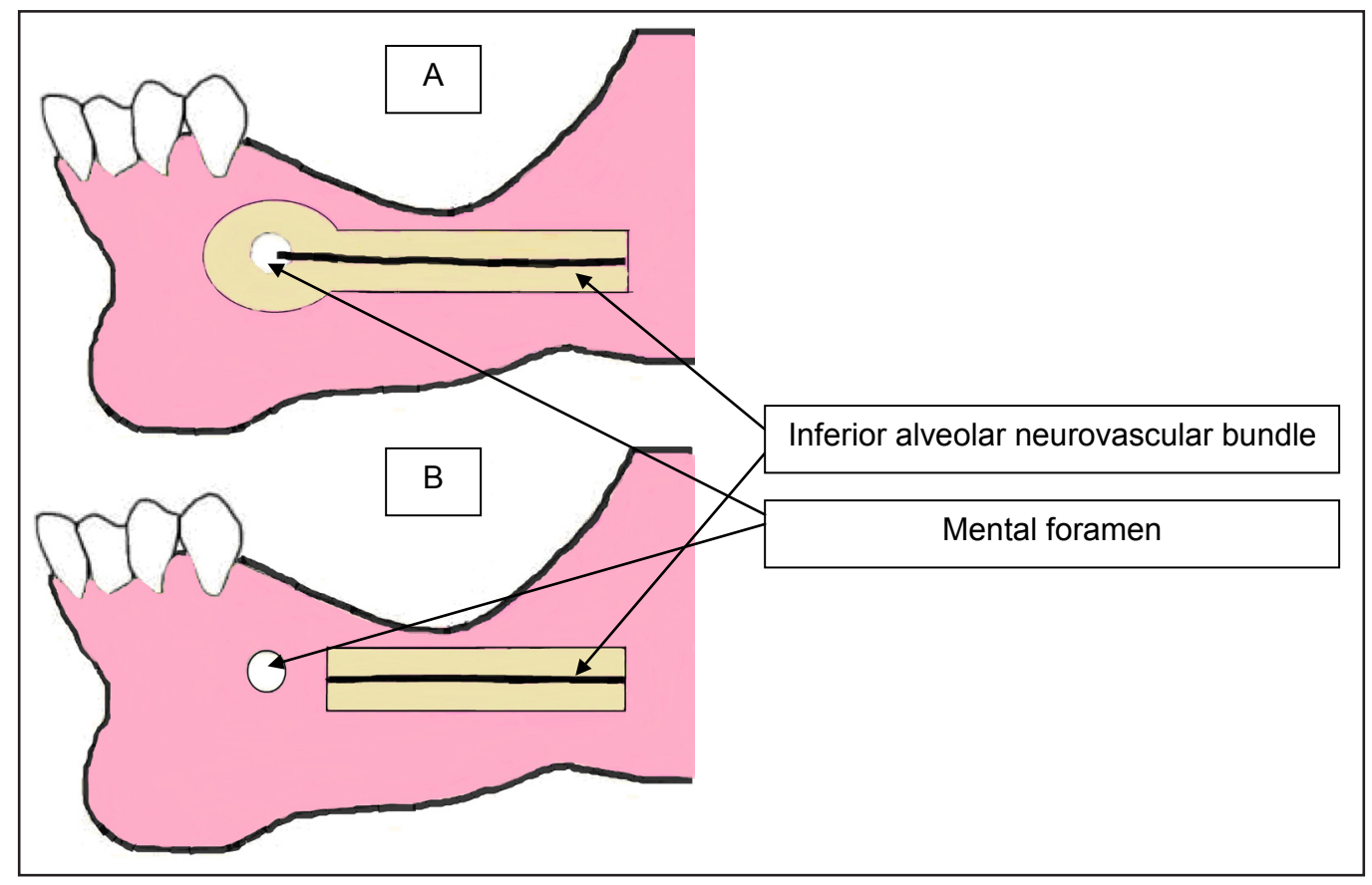

Figure 4. Schematic drawing showing the inferior alveolar neurovascular bundle transposition (A) and lateralization (B). 
Bone is removed using a round bur number 700 or 701, a straight handpiece and copious normal saline for irrigation or a piezosurgery device [9]. After removing the cortical bone, a curette may be used for removal of spongy bone and the cortical layer of the canal in cases where the cortical layer surrounding the canal is not dense or thick. A special instrument (Hassani nerve protector, Ali Hassani, Iran) [9] is required to protect the IAN while the cortical layer is removed using surgical burs or a piezosurgery device. Bone removal in close vicinity to the neurovascular bundle should be performed patiently and thoroughly. This is usually performed using special curettes parallel to the surface of the nerve bundles in an antero-posterior direction. Tiny bone spicules around the nerve should be removed. The area should be thoroughly irrigated so that the nerve bundle can be clearly seen [9]. The neurovascular bundle inside the canal is freed using special curettes and is moved laterally using a nerve hook. Then, a $10 \mathrm{~mm}$ wide gauze cord or elastic band is passed below the nerve to retract it from the surgical site in order to decrease the risk of ischemic trauma to the nerve. The second purpose of retracting the nerve from the surgical site during the operation is to reduce the risk of IAN damage [9]. After carefully freeing the nerve, the latter is separated using a vessel loop - while applying gentle traction outwards as the implants are positioned [27], the implant should be long enough to pass the MC and engage the basal body below the canal to achieve sufficient primary stability [9]. Finally, the vessel loop is removed and the nerve is replaced, positioning a resorbable membrane between it and the bone window to avoid direct contact with the implants. The procedure is completed by suturing the mucoperiosteal flap [27]. There is no interference with the incisive nerve [16]. The decision whether to use IANT or IANL depends on the amount of stretching that is needed in order to mobilize the IAN. According Lorean et al. study [1], stretching the nerve by $10-17 \%$ of its original length may result in disruption of the nerve fibers internally. In situations where only small traction is needed, ANL may be utilised. IANT is utilised when bigger amount of stretching is needed. Kan et al. [3] retrospective study demonstrated that the ND for IANT were $77.8 \%(7 / 9)$ and for the IANL $33.3 \%(4 / 12)$. As a summary of both surgical techniques (IANT and IANL), it can be concluded that IANL produces less side effects than IANT.

\section{The use of piezosurgery to avoid IAN damage}

Some studies recommend piezosurgery for bone removal in nerve transposition surgery. This device causes vibrations in the range of $20-200 \mu \mathrm{m}$ and cuts through the mineralized tissue completely and smoothly. If soft tissue or the neurovascular bundle comes in contact with this device, it stops functioning because it is designed to stop working when it contacts unmineralized tissue. This device is especially beneficial when a small osteotomy is going to be performed. Among the disadvantages of this device are the long duration of time that it takes to remove bone. Also, there remains controversy regarding the indications of piezosurgery devices, and some believe that the vibrations they generate may damage the nerve. Further investigations are required regarding indications of using piezosurgery devices in nerve transposition surgery $[\underline{9}, \underline{16}]$.

\section{Repositioning the neurovascular bundle inside the MC}

Before this phase, the surgeon should decide whether or not to place materials between the implant and the inferior alveolar neurovascular bundle. The preference is to place a collagen membrane or bone material between the implant and the inferior alveolar neurovascular bundle. A potential advantage of bone over a membrane is that, if proper healing occurs in the area, the contact area of implant and bone will increase. Before releasing the inferior alveolar neurovascular bundle from the elastic band, the mentioned material must be inserted between the neurovascular bundle and implant. This way, the inferior alveolar neurovascular bundle will be in a vent that is medially adjacent to the implants and covered by the mucoperiosteal flap. Alternatively, the inferior alveolar neurovascular bundle may be left to lie passively outside of the MC [9].

The bone defect is then covered by several methods: repositioning the bony window that was removed or the bony window can be crushed and mixed with an allograft or xenograft. The area is then sutured.

\section{Postoperative measures}

Antibiotic and corticosteroid prophylaxis is recommended because of the extensiveness and duration of surgery. Using corticosteroids pre- and post-operatively helps diminish the symptoms. However, there is no consensus in this regard; since inflammation can be among the causes of nerve dysfunction, corticosteroid therapy can be beneficial [9]. After analysing the current literature $[\underline{1}, \underline{2}, \underline{5}, \underline{13}, \underline{16}, \underline{24}, \underline{26}, \underline{27}]$ concerning IANL and IANT, several advantages and disadvantages of the procedures were found and are described below. 


\section{The advantages of the IANL and IANT}

- Longer implants can be placed in the same surgical step.

- Greater primary implant stability is provided thanks to the possibility of bicortical mandibular fixation. This technique avoids the need for additional radiation-intensive and costly imaging studies. Simple panoramic radiography and clinical examination are all that are required.

- Possibility of placement of a greater number of implants, which improves the overall strength of the final prosthesis.

- Possibility for simultaneous placement of implants during surgery, which allows a reduction in treatment time compared with other techniques as bone grafts that require a long waiting period before implant insertion together with additional surgeries.

- The option for immediate loading for the enhancement of masticatory function, dramatically improving the patient's quality of life.

- The evaluation values for implant survival rates are similar to those for standard implantation procedures.

- As a biomechanical advantage, IAN transposition presents an increase in resistance to occlusal forces and promotes a good proportion between the implant and the prosthesis.

- In addition, with this procedure, all of the following are accomplished:

- restoration of the correct vertical dimension;

- occlusal stability;

- chewing efficiency;

- prevention of tissues atrophy;

- replacement of dentures;

- stabilisation of the anterior dentition;

- temporomandibular joint and masticatory muscle balance.

\section{The disadvantages of the IANL and IANT}

One of the disadvantages of this procedure is that it does not recover alveolar ridge anatomy [14].

Another negative point of this procedure is that it temporarily weakens the mandible due to removal of cortical bone; which, in combination with implant placement, may lead to mandibular fracture at the operation site $[\underline{1}, \underline{2}, \underline{14}, \underline{16}, 24,27]$. According to Peleg [4], cylindrical non-threaded implants are recommended after the IANL procedure, as threaded implants in close contact with the nerve may cause neurosensory problems. This recommendation may be a disadvantage because non-threaded implants have a lower surface area compared to threaded implants, which decreases the stability of the implant. Since this surgical procedure is delicate, it is best performed under a general anesthesia to eliminate patient movement and to maximise access [2]. The general anaesthetic management of patients with myotonic dystrophy (dystrophia myotonica) can, however, be challenging [28].

The initial stability will depend only on the marginal cortical bone. The most common failures are due to bruxism and poor occlusal relations; therefore, patients with bruxism or poor occlusal relations make, implant stability and survival to less favourable. An additional disadvantage for such operations is the potential risk for osteomyelitis [13] .

\section{Limitations}

The main limitations of this review were that six authors [5,13-17] selected the patients randomly; in four studies $[\underline{1-3}, \underline{5}]$, the surgical procedure was not performed by the authors and, in two studies $[\underline{1}, \underline{3}]$, the method of implant osseointegration evaluation was not mentioned.

\section{CONCLUSIONS}

Inferior alveolar nerve repositioning is a technique that has been used for more than 20 years with good survival and survival rates. This is sometimes the only possible procedure to help patients to obtain a fixed prosthesis, especially in edentulous atrophic posterior mandibles. There are two main techniques for inferior alveolar nerve repositioning that are relatively safe and offer a high survival rate: inferior alveolar nerve lateralization and inferior alveolar nerve transposition. Increased protection of the neurovascular bundle is afforded during implant placement. Inferior alveolar nerve lateralization and transposition in combination with the installation of dental implants offer advantages, such as reducing the risk of inferior alveolar nerve damage. With careful pre-operative surgical and prosthetic planning, imaging, and extremely precise surgical technique, this procedure can be successfully used for implant placement in an edentulous atrophic posterior mandible.

\section{ACKNOWLEDGMENTS AND DISCLOSURE STATEMENTS}

The authors report no conflicts of interest related to this study. 


\section{REFERENCES}

1. Lorean A, Kablan F, Mazor Z, Mijiritsky E, Russe P, Barbu H, Levin L. Inferior alveolar nerve transposition and reposition for dental implant placement in edentulous or partially edentulous mandibles: a multicenter retrospective study. Int J Oral Maxillofac Surg. 2013 May;42(5):656-9. [Medline: 23481542] [doi: 10.1016/j.ijom.2013.01.020]

2. Morrison A, Chiarot M, Kirby S. Mental nerve function after inferior alveolar nerve transposition for placement of dental implants. J Can Dent Assoc. 2002 Jan;68(1):46-50. [Medline: 11844418]

3. Kan JY, Lozada JL, Goodacre CJ, Davis WH, Hanisch O. Endosseous implant placement in conjunction with inferior alveolar nerve transposition: an evaluation of neurosensory disturbance. Int J Oral Maxillofac Implants. 1997 JulAug;12(4):463-71. [Medline: 9274075]

4. Peleg M, Mazor Z, Chaushu G, Garg AK. Lateralization of the inferior alveolar nerve with simultaneous implant placement: a modified technique. Int J Oral Maxillofac Implants. 2002 Jan-Feb;17(1):101-6. [Medline: 11858565]

5. Khajehahmadi S, Rahpeyma A, Bidar M, Jafarzadeh H. Vitality of intact teeth anterior to the mental foramen after inferior alveolar nerve repositioning: nerve transpositioning versus nerve lateralization. Int J Oral Maxillofac Surg. 2013 Sep;42(9):1073-8. [Medline: 23706291] [doi: 10.1016/j.ijom.2013.04.012]

6. Alling CC. Lateral repositioning of inferior alveolar neurovascular bundle. J Oral Surg. 1977 May;35(5):419. [Medline: 265383]

7. Jensen O, Nock D. Inferior alveolar nerve repositioning in conjunction with placement of osseointegrated implants: a case report. Oral Surg Oral Med Oral Pathol. 1987 Mar;63(3):263-8. [Medline: 3473351] [doi: 10.1016/0030-4220(87)90187-3]

8. Rosenquist B. Fixture placement posterior to the mental foramen with transpositioning of the inferior alveolar nerve. Int J Oral Maxillofac Implants. 1992 Spring;7(1):45-50. [Medline: 1398823]

9. Hassani A, Motamedi MHK, Saadat S. Inferior alveolar nerve transpositioning for implant placement. Oral Maxillofac Surg. 2013 Jun;26. [URL: http://cdn.intechopen.com/pdfs/44588/InTech-Inferior alveolar nerve transpositioning for implant placement.pdf] [doi: $10.5772 / 52317]$

10. Chien PF, Khan KS, Siassakos D. Registration of systematic reviews: PROSPERO. BJOG. 2012 Jul;119(8):903-5. [Medline: 22703418] [doi: 10.1111/j.1471-0528.2011.03242.x]

11. Moher D, Liberati A, Tetzlaff J, Altman DG; PRISMA Group. Preferred reporting items for systematic reviews and metaanalyses: the PRISMA statement. Int J Surg. 2010;8(5):336-41. [Medline: 20171303] [doi: 10.1016/j.ijsu.2010.02.007]

12. Higgins JPT, Green S. Cochrane handbook for systematic reviews of interventions. Wiley, 2008:187-241. [URL: http://www.cochrane.org/cochrane-interventions-handbook]

13. Dal Ponte GL, Toledo GL, Toledo-Filho JL, Marzola C, Pastori CM, Zorzetto DL, Capelari MM. Lateralization and transposition use of the inferior alveolar nerve before the advent of short implants. Surgery and Maxillofacial Traumatology sponsored by the Hospital Association of Bauru - Base Hospital and the Brazilian College of Oral and Maxillofacial Surgery and Traumatology. [URL: http://www.actiradentes.com.br/revista/2011/textos/35RevistaATOUse of Lateralization and transposition-2011.pdf]

14. Vasconcelos Jde A, Avila GB, Ribeiro JC, Dias SC, Pereira LJ. Inferior alveolar nerve transposition with involvement of the mental foramen for implant placement. Med Oral Patol Oral Cir Bucal. 2008 Nov 1;13(11):E722-5. [Medline: 18978714$]$

15. Suzuki D, Bassi AP, Lee HJ, Alcântara PR, de Sartori IM, Luvizuto ER, Faco EF, Faot F. Inferior alveolar nerve lateralization and implant placement in atrophic posterior mandible. J Craniofac Surg. 2012 Jul;23(4):e347-9. [Medline: 22801178] [doi: 10.1097/SCS.0b013e31825655d1]

16. Chrcanovic BR, Custódio AL. Inferior alveolar nerve lateral transposition. Oral Maxillofac Surg. 2009 Dec;13(4):213-9. Review. [Medline: 19802637] [doi: 10.1007/s10006-009-0175-3]

17. Proussaefs P. Vertical alveolar ridge augmentation prior to inferior alveolar nerve repositioning: a patient report. Int J Oral Maxillofac Implants. 2005 Mar-Apr;20(2):296-301. [Medline: 15839125]

18. Ferrigno N, Laureti M, Fanali S. Inferior alveolar nerve transposition in conjunction with implant placement. Int J Oral Maxillofac Implants. 2005 Jul-Aug;20(4):610-20. [Medline: 16161746]

19. Kan JY, Lozada JL, Boyne PJ, Goodacre CJ, Rungcharassaeng K. Mandibular fracture after endosseous implant placement in conjunction with inferior alveolar nerve transposition: a patient treatment report. Int J Oral Maxillofac Implants. 1997 Sep-Oct;12(5):655-9. [Medline: 9337027]

20. Karlis V, Bae RD, Glickman RS. Mandibular fracture as a complication of inferior alveolar nerve transposition and placement of endosseous implants: a case report. Implant Dent. 2003;12(3):211-6. [Medline: 14560480]

21. Proussaefs P. Inferior alveolar nerve transposing in a situation with minimal bone height: a clinical report. J Oral Implantol. 2005;31(4):180-5. [Medline: 16145845] [doi: 10.1563/1548-1336(2005)31[180:IANTIA]2.0.CO;2] 
22. Gasparini G, Boniello R, Saponaro G, Marianetti TM, Foresta E, Torroni A, Longo G, Azzuni C, Cervelli D, Pelo S. Long term follow-up in inferior alveolar nerve transposition: our experience. Biomed Res Int. 2014;2014:170602. [Medline: 24949422] [PMC free article: 4052621] [doi: 10.1155/2014/170602]

23. Hashemi HM. A modified technique of inferior alveolar nerve repositioning: results in 11 patients. Acta Med Iran. 2006;44(4): 273-6. [URL: http://acta.tums.ac.ir/index.php/acta/article/viewFile/3131/2817]

24. Barbu HM, Levin L, Bucur MB, Comaneanu RM, Lorean A. A modified surgical technique for inferior alveolar nerve repositioning on severely atrophic mandibles: case series of 11 consecutive surgical procedures. Chirurgia (Bucur). 2014 Jan-Feb;109(1):111-6. [Medline: 24524480]

25. Cawood JI, Howell RA. A classification of the edentulous jaws. Int J OralMaxillofac Surg. 1988 Aug;17(4):232-6. [Medline: 3139793] [doi: 10.1016/S0901-5027(88)80047-X]

26. Del Castillo Pardo de Vera JL, Chamorro Pons M, Cebrián Carretero JL. Repositioning of the inferior alveolar nerve in cases of severe mandibular atrophy. a clinical case. Med Oral Patol Oral Cir Bucal. 2008 Dec 1;13(12):E778-82. [Medline: 19047966]

27. Quantius B. Lateralization of the inferior alveolar nerve. Report. Implants. 2010 Mar. [URL: http://www.dentaltribune. com/printarchive/download/document/14688/file/70fe9b6c8636972986229d4aeb1a1e76_18-21.pdf]

28. Campbell N, Brandom B, Day JW, Moxley T. Practical suggestions for the anaesthetic management of a myotonic dystrophy patient. Myotonic Dystrophy Foundation. Toolkit. p. 73-80. [URL: http://myotonic.org/sites/default/files/ pages/files/Anesthesia\%20Guidelines.pdf]

\section{To cite this article:}

Abayev B, Juodzbalys G. Inferior Alveolar Nerve Lateralization and Transposition for Dental Implant Placement. Part I: a Systematic Review of Surgical Techniques.

J Oral Maxillofac Res 2015;6(1):e2

URL: http://www.ejomr.org/JOMR/archives/2015/1/e2/v6n1e2.pdf doi: $10.5037 /$ jomr.2015.6102

Copyright (C) Abayev B, Juodzbalys G. Published in the JOURNAL OF ORAL \& MAXILLOFACIAL RESEARCH (http://www.ejomr.org), 31 March 2015.

This is an open-access article, first published in the JOURNAL OF ORAL \& MAXILLOFACIAL RESEARCH, distributed under the terms of the Creative Commons Attribution-Noncommercial-No Derivative Works 3.0 Unported License, which permits unrestricted non-commercial use, distribution, and reproduction in any medium, provided the original work and is properly cited. The copyright, license information and link to the original publication on (http://www.ejomr.org) must be included. 